\title{
Constructing a Phosphating-Nitriding Interface for Practically Used Lithium Metal Anode
}

Siyuan Li, ${ }^{\dagger, \|}$ Qilei Liu, ${ }^{\ddagger}, \|$ Xinyang Wang, ${ }^{\dagger}$ Qian Wu, ${ }^{\dagger}$ Lei Fan, ${ }^{\dagger}$ Weidong Zhang, ${ }^{\dagger}$ Zeyu Shen, ${ }^{\dagger}$

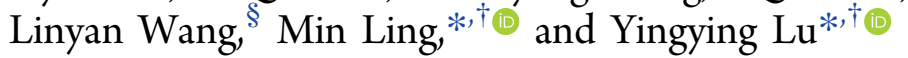

${ }^{\dagger}$ State Key Laboratory of Chemical Engineering, Institute of Pharmaceutical Engineering, College of Chemical and Biological Engineering, Zhejiang University, Hangzhou 310027, China

${ }^{\ddagger}$ Institute of Chemical Process Systems Engineering, School of Chemical Engineering, Dalian University of Technology, Dalian 116024, China

${ }^{\S}$ Department of Ophthalmology, The Second Affiliated Hospital, Zhejiang University School of Medicine, Hangzhou, Zhejiang 310009, China

\section{Supporting Information}

ABSTRACT: Low cycling reversibility and safety concerns are hindering the practical application of high-energy lithium metal batteries. Rational design of an artificial electrode/electrolyte interface is regarded as an effective way to circumvent the above problems. Herein, a phosphating-nitriding method is developed through the reaction between lithium metal and a $\mathrm{PCl}_{5}-\mathrm{LiNO}_{3}$ complex. An as-formed hybrid interface, consisting of $\mathrm{Li}_{3} \mathrm{~N}, \mathrm{Li}_{3} \mathrm{PO}_{4}$, and nanocrystalline $\mathrm{LiCl}$, offers high ionic conductivity and strong mechanical stability for uniform lithium electrodeposition. The dendrite-free behavior is further investigated through ex situ and in situ techniques. Accordingly, the modified $50 \mu \mathrm{m} \mathrm{Li}$ anode exhibits a highcurrent-density durability of $10 \mathrm{~mA} \mathrm{~cm} \mathrm{~cm}^{-2}$ and a long-term cycling performance of greater than $300 \mathrm{~h}$ at a high Li-metal utilization of $30.6 \%$ under a conventional EC/DEC electrolyte. A full cell paired with a high-voltage cathode $\mathrm{LiNi}_{0.5} \mathrm{Co}_{0.2} \mathrm{Mn}_{0.3} \mathrm{O}_{2}$ (NCM523) displays a 4-fold improvement in cell lifetime under a low negative to positive electrode capacity ratio ( $\mathrm{N} / \mathrm{P}$ ratio) of 3.92 . This work paves a new way to construct an advanced artificial interface for next-generation high-capacity/high-voltage Li-metal-based batteries.

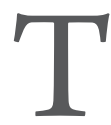
he current lithium ion battery (LIB) consisting of a graphite anode $\left(372 \mathrm{mAh} \mathrm{g}^{-1}\right)$ and a transition metal oxide cathode has reached its theoretical energy density $\left(\leq 250 \mathrm{Wh} \mathrm{kg}^{-1}\right)$ and cannot meet the needs of large electric equipment. ${ }^{1-3}$ To promote the energy density of batteries, lithium metal with high theoretical specific capacity and the lowest electrochemical potential $\left(3860 \mathrm{mAh} \mathrm{g}^{-1}\right.$, $-3.04 \mathrm{~V}$ vs standard hydrogen electrode) and cathodes with aggressive chemistries, such as $\mathrm{Li}-\mathrm{S}$ and $\mathrm{Li}-\mathrm{O}_{2}$, are explored. ${ }^{4,5}$ Such configuration, offering an energy density exceeding $500 \mathrm{Wh} \mathrm{kg}^{-1}$, is considered to be an attractive power system for future electric vehicles and unmanned aircraft. ${ }^{6,7}$

To realize the commercialization of lithium metal batteries (LMBs), basic research issues and industrial amplification need to be carefully considered. Due to the high reactivity, lithium metal can react with an electrolyte to form an intrinsic unstable solid electrolyte interface (SEI) on its surface. ${ }^{8}$ The heterogenous mosaic-like SEI cannot endure the large electrode expansion, and fresh $\mathrm{Li}$ will be consumed, resulting in a low Coulombic efficiency (CE) and harmful dendrite growth. Such irreversibility impedes further industrialization, because the anode capacity utilized in a practical cell is limited (negative to positive electrode capacity ratio, N/P ratio < 1.5). ${ }^{9,10}$ The exhaustion of the lithium source becomes the main reason for battery failure, rather than dendrite growth or an internal short circuit. ${ }^{11}$

Various strategies have been proposed to protect the Limetal anode and improve its reversibility in a liquid-state cell. Accommodating $\mathrm{Li}$ in a $3 \mathrm{D}$ host framework effectively alleviates the large volume expansion during cycling and

Received: September 30, 2019

Accepted: November 18, 2019

Published: November 18, 2019 


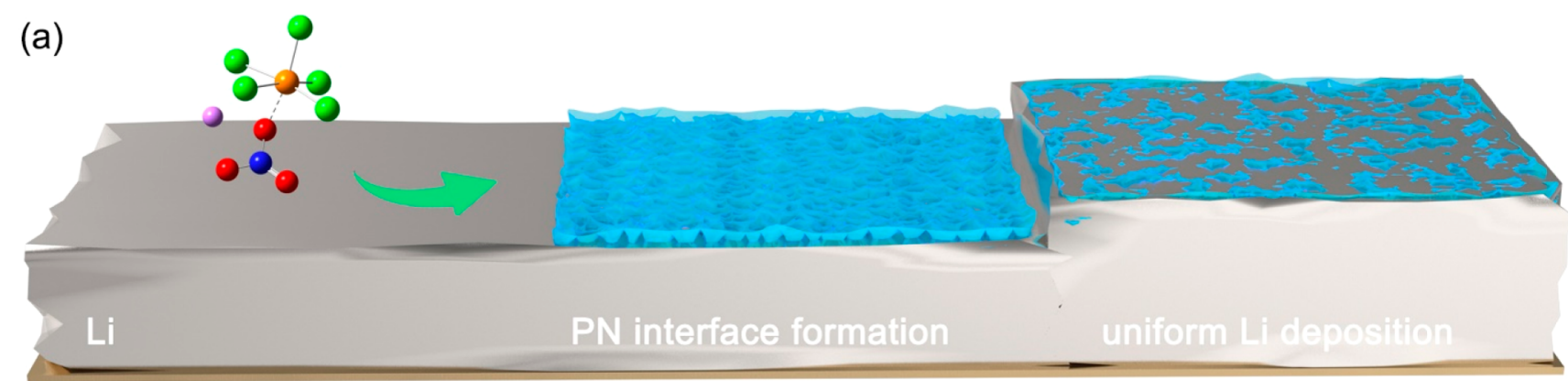

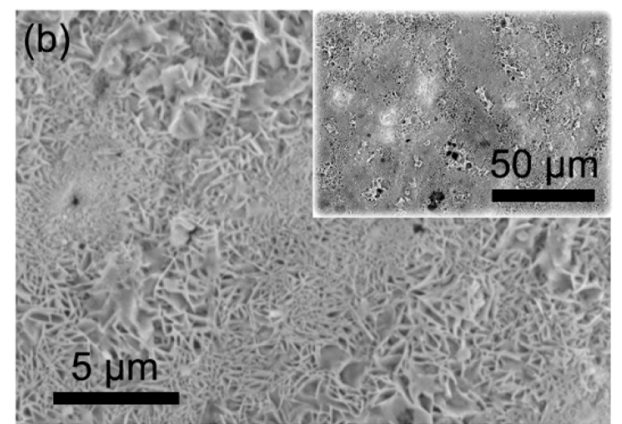

(e)

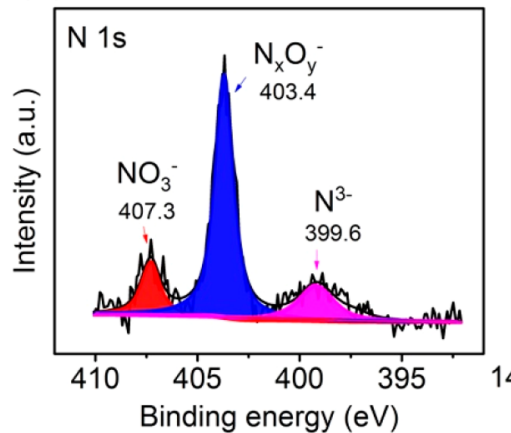

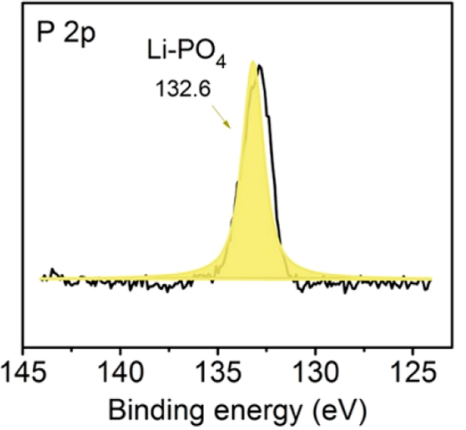
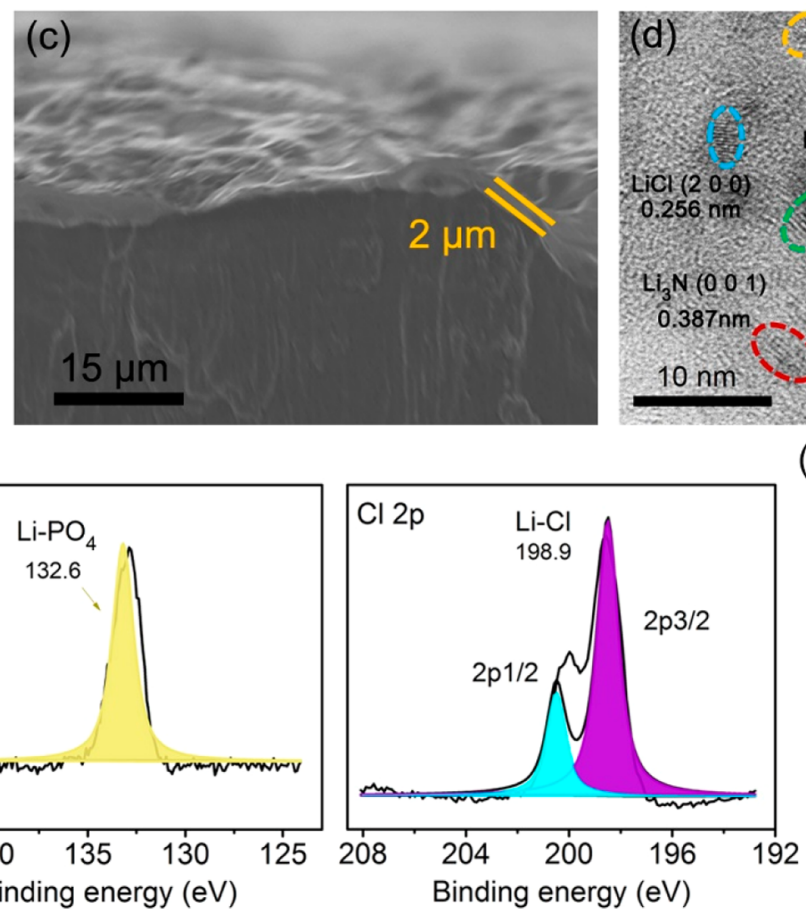

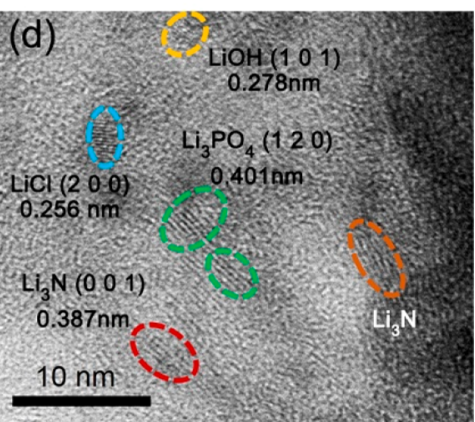

(f)

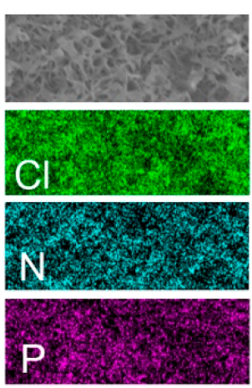

Figure 1. Preparation and characterizations of the PN interface on a Li anode. (a) Schematic illustration of formation of PN interface on Li metal. (b) Top-view SEM image and (c) cross-sectional SEM image of PN-Li anode. (d) High-resolution TEM image of PN interface. (e) XPS spectra of N 1s, P 2p, and Cl 2p for PN interface. (f) EDS elemental mapping images of $\mathrm{Cl}, \mathrm{N}$, and P for PN-Li anode.

meanwhile lowers the local current density. ${ }^{12-16}$ Artificial SEIs with high $\mathrm{Li}$ ionic conductivity can mechanically suppress the dendrite growth. ${ }^{17-21}$ Tailoring electrolyte components such as $\mathrm{Li}$ salts, additives, and solvents can in situ form a chemically stable SEI layer to enhance plating efficiency. ${ }^{22-30}$ In general, the key towards a dendrite-free anode is to construct a protective layer that is ionically conductive, electronic insulating, mechanically robust, and electrochemically stable to regulate the deposition behavior of lithium metal. ${ }^{31,32}$ Moreover, although these efforts have been proven to be effective to some extent, the lifespan test under practical conditions (for example, using $50 \mu \mathrm{m} \mathrm{Li} \mathrm{foils)} \mathrm{is} \mathrm{still} \mathrm{a} \mathrm{huge}$ challenge for the Li-metal anode. Combining ultrathin Li-metal foils with a high areal capacity cathode $\left(>2.5 \mathrm{mAh} \mathrm{cm}^{-2}\right)$ would be indispensable to examine the expected effect in a real soft-package cell. ${ }^{33}$

Herein, a phosphating-nitriding interface (denoted as a PN interface) strategy is proposed via a reaction between an ultrathin lithium anode and a $\mathrm{PCl}_{5}-\mathrm{LiNO}_{3}$ complex to smooth the lithium deposition on interface. The complex gradually decomposes on the lithium surface to form a dense and stable interface consisting of inorganic $\mathrm{Li}_{3} \mathrm{PO}_{4}, \mathrm{Li}_{3} \mathrm{~N}$, and nanocrystalline $\mathrm{LiCl}$. Owing to the fast $\mathrm{Li}$-ion conductor and strong mechanical stability of the polycrystalline inorganic interface, the homogeneous lithium electrodeposition behavior of the $\mathrm{PN}-\mathrm{Li}$ anode can be observed through ex situ focused ion beam scanning electron microscopy (FIB-SEM) and in situ optical microscope. Meanwhile, the modified $50 \mu \mathrm{m} \mathrm{Li}$ anode exhibits a high-current-density durability of $10 \mathrm{~mA} \mathrm{~cm}^{-2}$ and a long-term cycling performance of greater than $300 \mathrm{~h}$ under a high areal capacity loading of $3 \mathrm{~mA} \mathrm{~h} \mathrm{~cm}{ }^{-2}$. Full cells paired with a high-voltage cathode $\mathrm{LiNi}_{0.5} \mathrm{Co}_{0.2} \mathrm{Mn}_{0.3} \mathrm{O}_{2}$ (NCM523) or $\mathrm{LiFePO}_{4}$ display an obvious improvement in cell lifetime under a low N/P ratio of 3.92 .

The procedures for preparing an $\mathrm{PN}$ interface are detailed in the experimental section and schematically illustrated in Figure 1a. Firstly, $\mathrm{PCl}_{5}$ and $\mathrm{LiNO}_{3}$ are dissolved in dimethyl ether (DME) solvent to obtain a transparent solution, after which two solutions are mixed together to form a yellow solution (Figure S1). Raman spectra show the almost same pattern before and after mixing, indicating the chemical reaction between $\mathrm{PCl}_{5}$ and $\mathrm{LiNO}_{3}$ does not change the solvent structure (Figure S2). Then, lithium metal is immersed into a single or mixed solution for $24 \mathrm{~h}$, separately. As can be seen, the lithium foils in pure $\mathrm{DME}$ and $\mathrm{LiNO}_{3}$-containing solution show the shiny surface after soaking, revealing that $\mathrm{LiNO}_{3}$ salt 
(a)

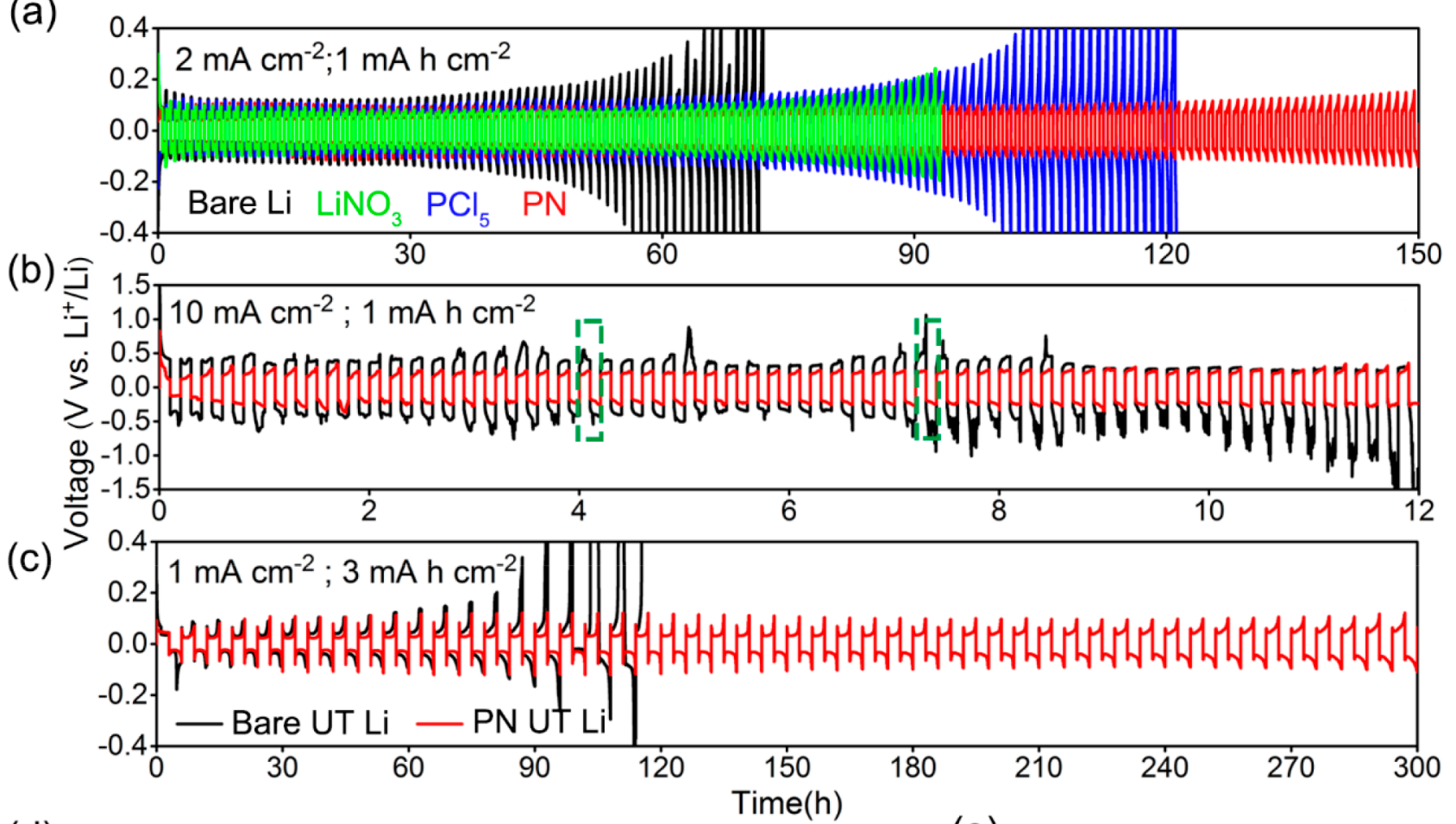

(d)
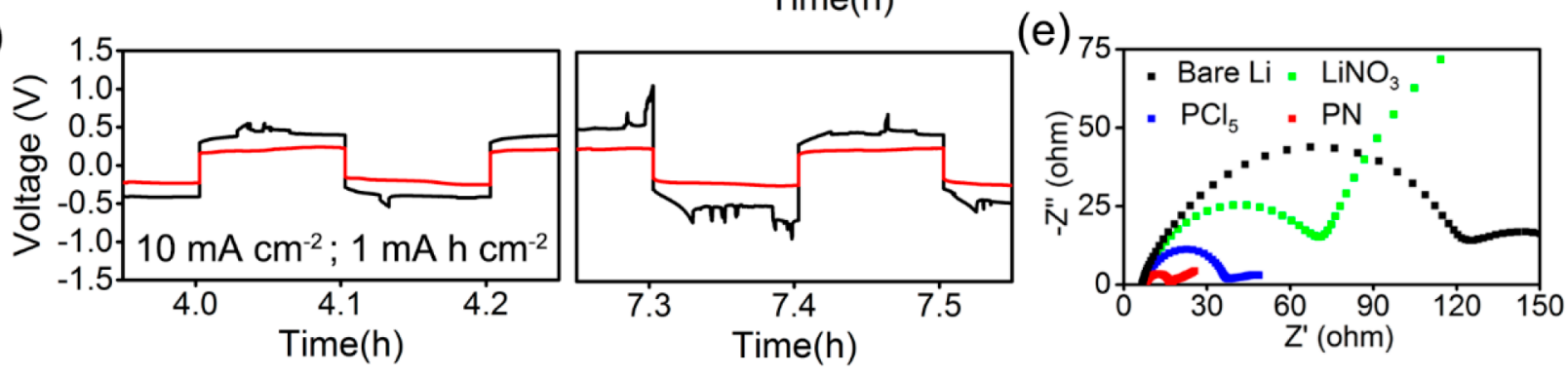

Figure 2. Cycling performance of symmetrical cells using PN-Li electrode. (a) Voltage profiles of bare, $\mathrm{LiNO}_{3}, \mathrm{PCl}_{5}$, and $\mathrm{PN}_{\text {treated }} \mathrm{Li}$ anode at $2 \mathrm{~mA} \mathrm{~cm}^{-2}$ and $1 \mathrm{~mA} \mathrm{~h} \mathrm{~cm}$. Voltage profiles of $\mathrm{PN}-\mathrm{Li}$ anode at (b) $10 \mathrm{~mA} \mathrm{~cm}$ and $1 \mathrm{~mA} \mathrm{~h} \mathrm{~cm}^{-2}$ and (c) $1 \mathrm{~mA} \mathrm{~cm}$ and $3 \mathrm{~mA} \mathrm{~h}$ $\mathrm{cm}^{-2}$. (d) Enlargement of green bar in (b). e) Nyquist plot of the impedance spectra of the Li anode treated by different materials.

and solvent almost remain stable against lithium metal and it is hard for them to form an effective protective layer under normal condition. As a comparison, the surfaces of lithium foils in $\mathrm{PCl}_{5}$ - and $\mathrm{PN}$-containing solution turns to yellow and gray, indicating that adding $\mathrm{PCl}_{5}$ into $\mathrm{LiNO}_{3}-\mathrm{DME}$ solution absolutely changes the reaction behavior as compared with each single one (Figure S3). Scanning electronic microscopy (SEM), high-resolution transmission electron microscopy (HRTEM), and X-ray photoelectron spectroscopy (XPS) were conducted to investigate the detailed compositions of the PN interface. Before immersion, the pristine $\mathrm{Li}$ shows a relatively smooth surface with some slip lines (Figure S4a). The $\mathrm{Li}$ anode possesses an ultrathin thickness of $50 \mu \mathrm{m}$, corresponding to a specific capacity of $9.8 \mathrm{~mA} \mathrm{~h} \mathrm{~cm}{ }^{-2}$ (Figure $\mathrm{S} 4 \mathrm{~b}, \mathrm{c})$. For a $\mathrm{Li}$ anode exposed to mixed $\mathrm{PN}$ solution, an asformed interface is composed of a nanoflake-like structure from top-view, which is different from the dense structure formed in $\mathrm{PCl}_{5}$ solution (Figures $\mathrm{lb}$ and S5). This protective layer with a thickness of $2 \mu \mathrm{m}$ tightly adheres to the Li surface, which is beneficial to maintain the integrity of interface/ electrode during cycling (Figure 1c). HRTEM is utilized to further identify the composition of the PN coating. Compared with a routine SEI layer formed in EC/DEC electrolyte, the polycrystalline nature of inorganic nanoparticles in the $\mathrm{PN}$ layer is demonstrated by selected area electron diffraction (Figure S6). A high-resolution TEM image (Figure 1d) demonstrates the existence of noncrystal phases and ultrafine nanocrystals with sizes ranging from 2 to $5 \mathrm{~nm}$ in PN interface. The lattices spacing of $0.387,0.401$, and $0.256 \mathrm{~nm}$ can be attributed to the typical lattice planes of $\mathrm{Li}_{3} \mathrm{~N}(001), \mathrm{Li}_{3} \mathrm{PO}_{4}$ (120), and $\mathrm{LiCl}$ (200). This result is also validated by XPS measurement (Figure 1e). From $\mathrm{N}$ 1s spectra, the peaks located at 407.3, 402.4, and $399.6 \mathrm{eV}$ can be ascribed to $\mathrm{NO}_{3}{ }^{-}$, $\mathrm{N}_{x} \mathrm{O}_{y}{ }^{-}$and $\mathrm{N}_{3}{ }^{-}$, respectively. The $\mathrm{P} 2 \mathrm{p}$ and $\mathrm{Cl} 2 \mathrm{p}$ spectra indicate that the $\mathrm{PCl}_{5}$ decomposes into phosphate and lithium chloride, which is consistent with the observation results in HRTEM. The energy dispersive spectroscopy (EDS) elemental mapping shows a uniform element distribution of $\mathrm{Cl}$, $\mathrm{N}$, and $\mathrm{P}$, reflecting that the nanocrystals are well-distributed in the whole interface. Owing to the fast Li-ion conducting property of $\mathrm{Li}_{3} \mathrm{~N}$ and $\mathrm{LiN}_{x} \mathrm{O}_{y}$ and the strong mechanical stability of inorganic nanoparticles, it is reasonable that the PN layer can reinforce the interface stability and homogenize the Li-ion flux at the electrode/electrolyte interface. The detailed formation process of the PN interface is also detected by density functional theory (DFT) calculation and nuclear magnetic resonance (NMR) spectra. From Table S1, the energy change by the complexation between each $\mathrm{PCl}_{5}-$ 

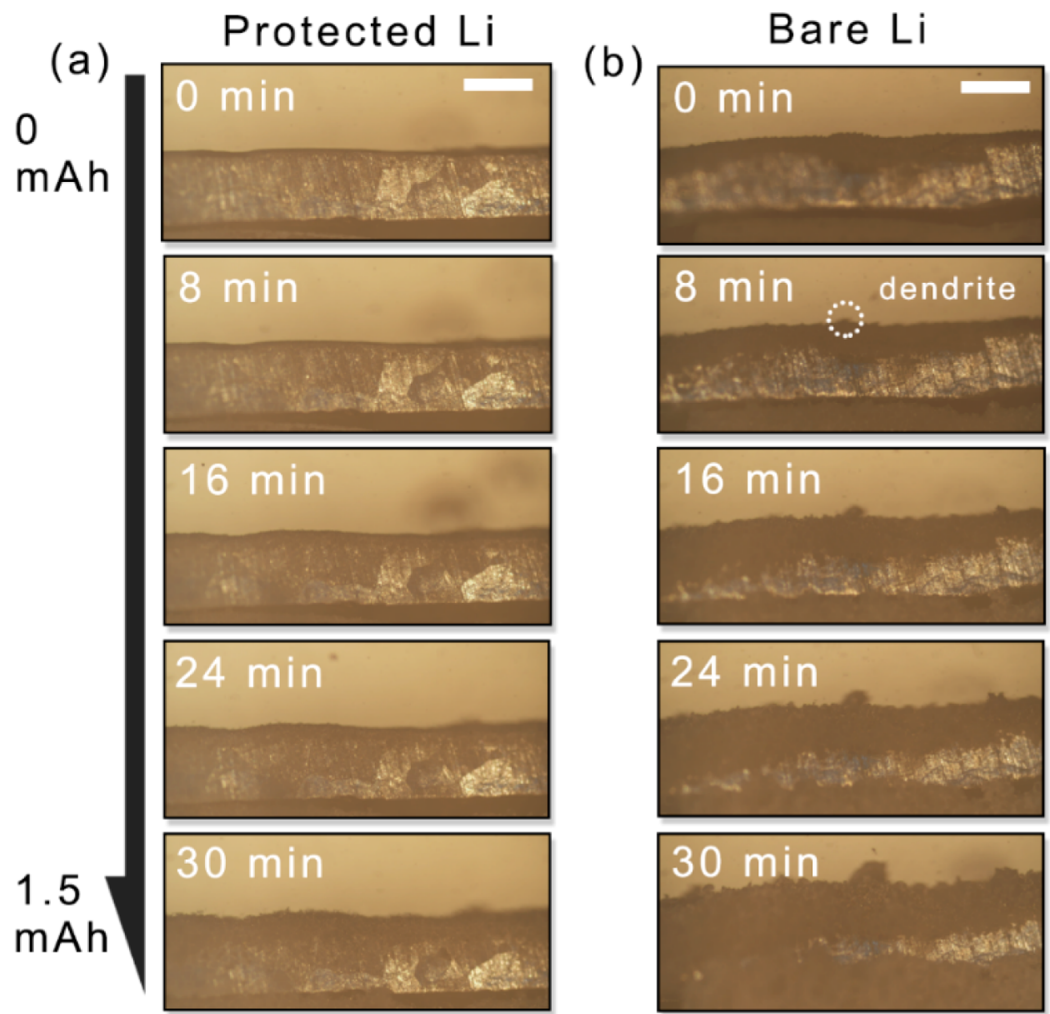

(f)
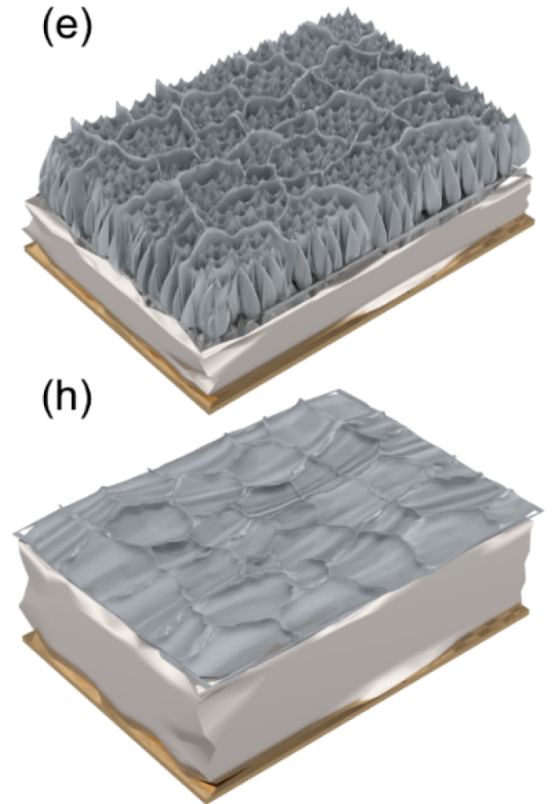
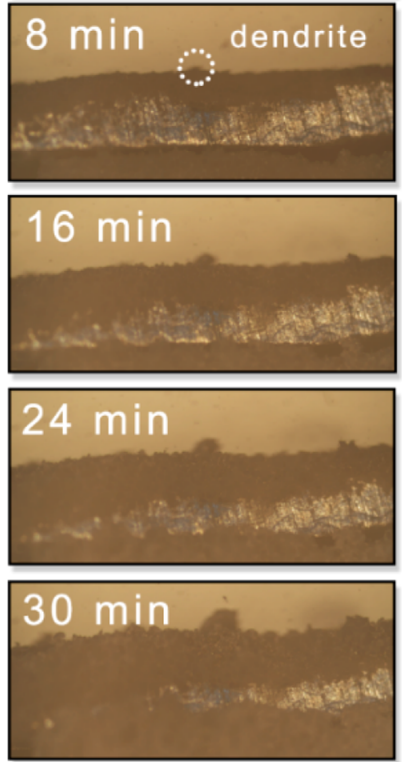

(c)

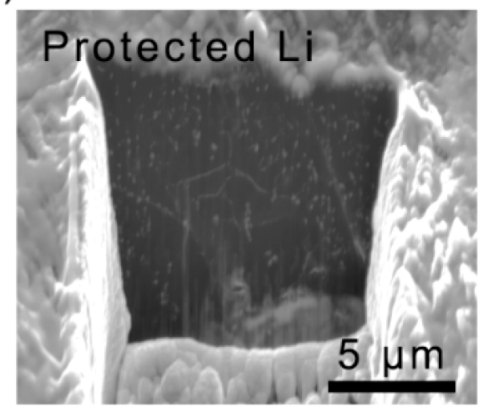

(d)
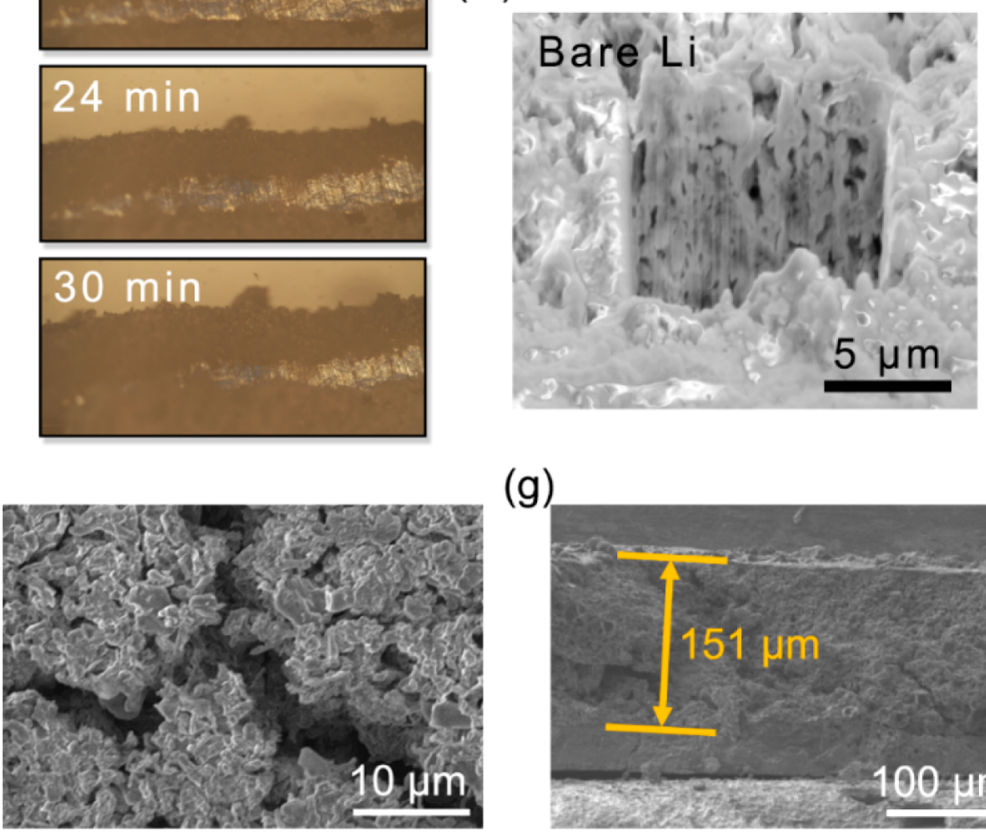

(i)

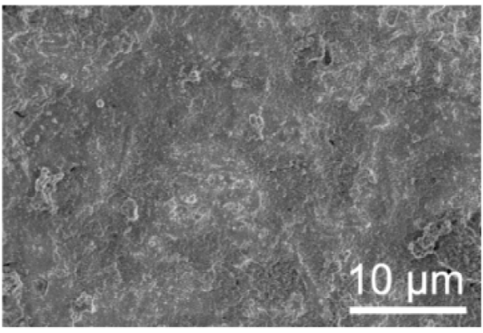

(g)

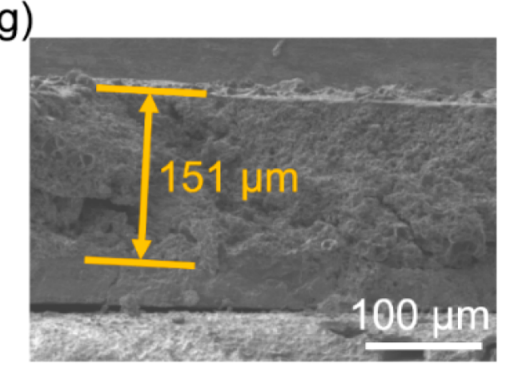

(j)

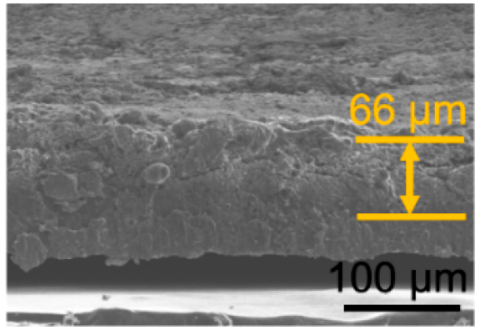

Figure 3. Morphology of cycled Li and the deposition behavior analysis. In situ optical microscopy observations of the electrode/electrolyte interface during electrodeposition on (a) PN-Li and (b) bare $\mathrm{Li}$ under a current density of $3 \mathrm{~mA} \mathrm{~cm}{ }^{-2}$. (c) Cross-sectional FIB images of (c) $\mathrm{PN}-\mathrm{Li}$ and (d) bare $\mathrm{Li}$ after 20 cycles at $1 \mathrm{~mA} \mathrm{~cm}^{-2}$ and $3 \mathrm{~mA} \mathrm{~h} \mathrm{~cm}^{-2}$. (e,h) Schematic diagrams of remaining active Li on bare Li and PN$\mathrm{Li}$ after long cycling. (f,i) Top-view and (g,j) cross-sectional SEM images of bare $\mathrm{Li}$ and PN-Li anodes after $30 \mathrm{cycles}^{\mathrm{at}} 1 \mathrm{~mA} \mathrm{~cm}^{-2}$ and 3 $\mathrm{mA} \mathrm{h} \mathrm{cm} \mathrm{cm}^{-2}$.

$\mathrm{LiNO}_{3}$ pair is determined to be $-0.297 \mathrm{eV}$, which can be translated to $-28.64 \mathrm{~kJ} \mathrm{~mol}^{-1}$. It suggests that the complexation between $\mathrm{PCl}_{5}$ and $\mathrm{LiNO}_{3}$ is favorable, as the energy of the $\mathrm{PCl}_{5}-\mathrm{LiNO}_{3}$ binary system is lower after complexation. The ${ }^{31} \mathrm{P}$ NMR spectra of the PN solution also show an obvious $\mathrm{PCl}_{5}$ peak at $-84 \mathrm{ppm}$ at the beginning (Figure S7), indicating the existence of $\mathrm{PCl}_{5}-\mathrm{LiNO}_{3}$ complex. After $\mathrm{Li}$ foil immersion, the ${ }^{31} \mathrm{P}$ peaks at $-3.5,-3.8$ and $-4.6 \mathrm{ppm}$ can be observed, which are attributed to the decomposition intermediate due to the $\mathrm{P}-\mathrm{Cl}$ cleavage. After immersion for $24 \mathrm{~h}$, the complex is fully transformed to phosphate $(\sim 0 \mathrm{ppm})$, which is in accordance with the XPS results. The supposed reaction mechanism is evaluated through DFT calculations thermodynamically (Figure S8). In the pure $\mathrm{LiNO}_{3} / \mathrm{DME}$ electrolyte, lithium nitrate can spontaneously react with metallic lithium to form $\mathrm{Li}_{3} \mathrm{~N}$. However, its reaction thermodynamic tendency is 
small $(\Delta G=-29.485 \mathrm{eV})$. When the $\mathrm{PCl}_{5}-\mathrm{LiNO}_{3}$ complex was applied, the reaction Gibbs free energy changes $\Delta G$ equal to $-177.135 \mathrm{eV}$ (decomposition products: $\mathrm{Li}_{3} \mathrm{~N}$ ) and -51.799 $\mathrm{eV}$ (decomposition products: $\mathrm{LiNO}_{2}$ ), indicating that the reaction is more favorable for the $\mathrm{PCl}_{5}-\mathrm{LiNO}_{3}$ complex and $\mathrm{Li}$ than for pure $\mathrm{LiNO}_{3}$ and $\mathrm{Li}$.

Galvanostatic charge/discharge measurements were performed under a carbonate-based electrolyte without additives to evaluate the cell lifetime of the modified $50 \mu \mathrm{m} \mathrm{Li}$ anode. The solvent type and material ratio are studied to determine the optimal conditions for interface formation. In Figure S9, the cell prepared using the $\mathrm{PCl}_{5}-\mathrm{LiNO}_{3}$ complex with a mass ratio of 5:1 dissolved in DME shows the longest lifespan of more than $180 \mathrm{~h}$ compared with that using mass ratios of 5:2 or 7.5:1. Then, ester-based electrolyte was used to evaluate the effects of solvent types on the interface formed (Figure S10). Compared with the high reactivity of EC to form the heterogeneous mosaic-like SEI, the SEI formed in DME solution becomes more homogenous, thus rendering an even $\mathrm{Li}^{+}$flux on PN interface. As a comparison, the single $\mathrm{LiNO}_{3}$ and $\mathrm{PCl}_{5} / \mathrm{DME}$ treated cells were also investigated to study their interfacial stability (Figure 2a, top). The interface obtained in $5 \% \mathrm{LiNO}_{3} / \mathrm{DME}$ solution is easy to be washed away and shows limited protection on deposited Li (lifetime $95 \mathrm{~h}$ ). For the interface obtained in $\mathrm{PCl}_{5} / \mathrm{DME}$ solution, due to the lack of lithium nitride that rapidly conducts lithium ions, the cell also exhibits a middle lifespan of $120 \mathrm{~h}$ under a current density of $2 \mathrm{~mA} \mathrm{~cm}^{-2}$ with a fixed capacity of $1 \mathrm{~mA} \mathrm{~h} \mathrm{~cm}$. Inheriting the advantages of nitride and phosphide, the $\mathrm{PN} / \mathrm{Li}$ anode shows a stable voltage profile with a small hysteresis of about $50 \mathrm{mV}$ for more than $320 \mathrm{~h}$, while the bare $\mathrm{Li}$ anode quickly fails after just $170 \mathrm{~h}$ of cycling under the current density of $1 \mathrm{~mA} \mathrm{~cm}^{-2}$ (Figure S11a). When the current density increases to $5 \mathrm{~mA} \mathrm{~cm}{ }^{-2}$, dead lithium rapidly grows during each plating and stripping process in the bare Li-metal cell, resulting in a depletion of the lithium source over 40 cycles. In contrast, the $\mathrm{PN}-\mathrm{Li}$ anode offers a fast ion transport pathway and enough mechanical strength for uniform $\mathrm{Li}$ deposition, leading to an excellent lithium retention for more than 100 cycles (Figure S11b). Even in an extreme condition of $10 \mathrm{~mA}$ $\mathrm{cm}^{-2}$, the fast ion migration in the $\mathrm{PN}$ interface can also guarantee the smooth operation of symmetrical cells for more than 60 cycles, while a bare $\mathrm{Li}$ cell represents random voltage curves with sluggish ion transport kinetics (Figure 2b). The detailed voltage profiles are represented in Figure $2 \mathrm{~d}$; the curve of bare $\mathrm{Li}$ anode shows lots of burrs, reflecting severe side reactions or an internal short circuit under such a high current density. However, the $\mathrm{PN}-\mathrm{Li}$ anode exhibits nearly constant voltage hysteresis $(\sim 250 \mathrm{mV})$, implying the outstanding stability and compatibility of PN at the anode interface. In addition, a high areal capacity of $3 \mathrm{~mA} \mathrm{~h} \mathrm{~cm}{ }^{-2}$ for commercial use was tested to verify the stability of $\mathrm{PN}$ interface against large volume change (Figures $2 \mathrm{c}$ and S11c). The routine SEI on a bare $\mathrm{Li}$ anode is brittle and easily damaged by a sharp $\mathrm{Li}$ dendrite and surface fluctuation, which leads to a short lifetime of $110 \mathrm{~h}$ under the current density of $1 \mathrm{~mA} \mathrm{~cm}{ }^{-2}$. In contrast, the $\mathrm{PN}-\mathrm{Li}$ cell can cycle more than $300 \mathrm{~h}$ without failure. The fast ionic pathway of the PN layer is also proven by electrochemical impedance spectra measurement in that PN interface possesses the lowest interfacial resistance $(\sim 10 \Omega$ in the first cycle, Figure 2e). The long lifespan of modified $\mathrm{Li}$ can be ascribed to the high cyclic Coulombic efficiency upon the PN interface (Figure S12). The PN-Li delivers $7.99 \mathrm{~mA} \mathrm{~h}$ of active $\mathrm{Li}$ (CE: 96.12\%) after 51 cycles in the EC/DEC electrolyte under the conditions of $1 \mathrm{~mA} \mathrm{~cm}^{-2}$ and $0.5 \mathrm{~mA} \mathrm{~h}$ $\mathrm{cm}^{-2}$, which is much higher than bare $\mathrm{Li}(6.80 \mathrm{~mA} \mathrm{~h}, \mathrm{CE}=$ 91.45\%). When adding 30 wt \% fluorinated carbonate into DEC, the CE of PN-modified Li can reach $98.04 \%$. The high reversible capability of the $\mathrm{PN}$ interface is indispensably important to reduce the irreversible consumption of active $\mathrm{Li}$ materials.

The morphology of $\mathrm{Li}$ electrodeposits on the PN interface and bare Li can be probed directly using optical visualization studies. All cells were operated under a fixed current density of $3 \mathrm{~mA} \mathrm{~cm}{ }^{-2}$ for $30 \mathrm{~min}$ to obtain the optical images. For the bare $\mathrm{Li}$ symmetrical cell, mossy $\mathrm{Li}$ electrodepositions are apparent as early as $8 \mathrm{~min}$ after the beginning of deposition. The uneven loose $\mathrm{Li}$ deposits are ramified growth on the surface of the $\mathrm{Li}$ anode, triggering the irreversible $\mathrm{Li}$ consumption and a severe safety hazard. The $\mathrm{PN}-\mathrm{Li}$ anode shows a smooth $\mathrm{Li}$ deposition behavior without obvious $\mathrm{Li}$ protrusion (Figure 3a,b). Figure S13 provides more detailed information about $\mathrm{Li}$ deposition at $0.8 \mathrm{~mA} \mathrm{~h}$. Sliced focused ion beam (FIB) images reveal the morphology evolution beneath the SEI (Figure 3c,d). After cross-sectioning by a $\mathrm{Ga}^{+}$ ion beam, $\mathrm{PN}-\mathrm{Li}$ exhibits a dense and compact $\mathrm{Li}$ deposition (black region) under the PN layer (white layer). The PN layer is tightly adhered to the $\mathrm{Li}$ surface without any interspace, indicating a good conformal ability of the PN layer. For the cycled bare Li, FIB images offer the textural information that $\mathrm{Li}$ deposition is porous, which means that a large volume expansion as well as accumulated SEI formation occurs after cycling (Figure S14). With the continuous plating and stripping process, the fragile SEI cannot endure such a large volume change, and fresh $\mathrm{Li}$ is exposed to the electrolyte to generate more SEI, which conversely aggravates the active $\mathrm{Li}$ consumption and dead Li formation (Figure 3e). SEM images confirm this behavior that the $\mathrm{Li}$ source is completely exhausted. The surface of the bare $\mathrm{Li}$ anode is full of disordered $\mathrm{Li}$ dendrites, and the electrode thickness dramatically increases to $150 \mu \mathrm{m}, 3$-fold thicker than pristine $\mathrm{Li}$ (Figure 3f,g). In contrast, the PN interface can effectively insulate electrolyte intrusion, and fresh $\mathrm{Li}$ can finely protect beneath the SEI interface (Figure $3 \mathrm{~h}$ ). As a result, the cycled $\mathrm{Li}$ exhibits a flatter surface morphology and small volume exchange of $66 \mu \mathrm{m}$ due to the smooth deposition kinetics (Figure $3 \mathrm{i}, \mathrm{j}$ ). Ex situ XPS shows that the nitrate fully changes to $\mathrm{Li}_{3} \mathrm{~N}$, and the peaks of $\mathrm{Cl} 2 \mathrm{p}$ and $\mathrm{P} 2 \mathrm{p}$ can still be detected, indicating the PN interface finely coats the Li surface after 30 cycles (Figure S15).

The commercial process of the lithium metal anode encounters many difficulties. The most significant indicator for practical application of lithium metal batteries is the N/P ratio. However, many measurements are carried out under a $\mathrm{Li}$ unlimited condition with a small cathode loading $(500 \mu \mathrm{m}$ thick $\mathrm{Li}$ and $\mathrm{N} / \mathrm{P}$ ratio $>50$ ). In this kind of configuration, cells always fail due to an internal short circuit or accumulated resistance rather than $\mathrm{Li}$ source depletion, which cannot reflect a practical cycling condition of real utilization. Therefore, it is urgent to design a full cell test with a low N/P ratio and high cathode loading for industrialization. In this work, we utilized the limited $\mathrm{Li}$ anode to pair with $\mathrm{LiFePO}_{4}$ (LFP) and $\mathrm{LiNi}_{0.5} \mathrm{Co}_{0.2} \mathrm{Mn}_{0.3} \mathrm{O}_{2}$ (NCM523) to validate the cycling ability under a anode controlling condition. The characterizations of the LFP and NCM cathodes are exhibited in Figure S16. The LFP and NCM electrodes offer an areal capacity of 1.5 and 2.5 
(a)
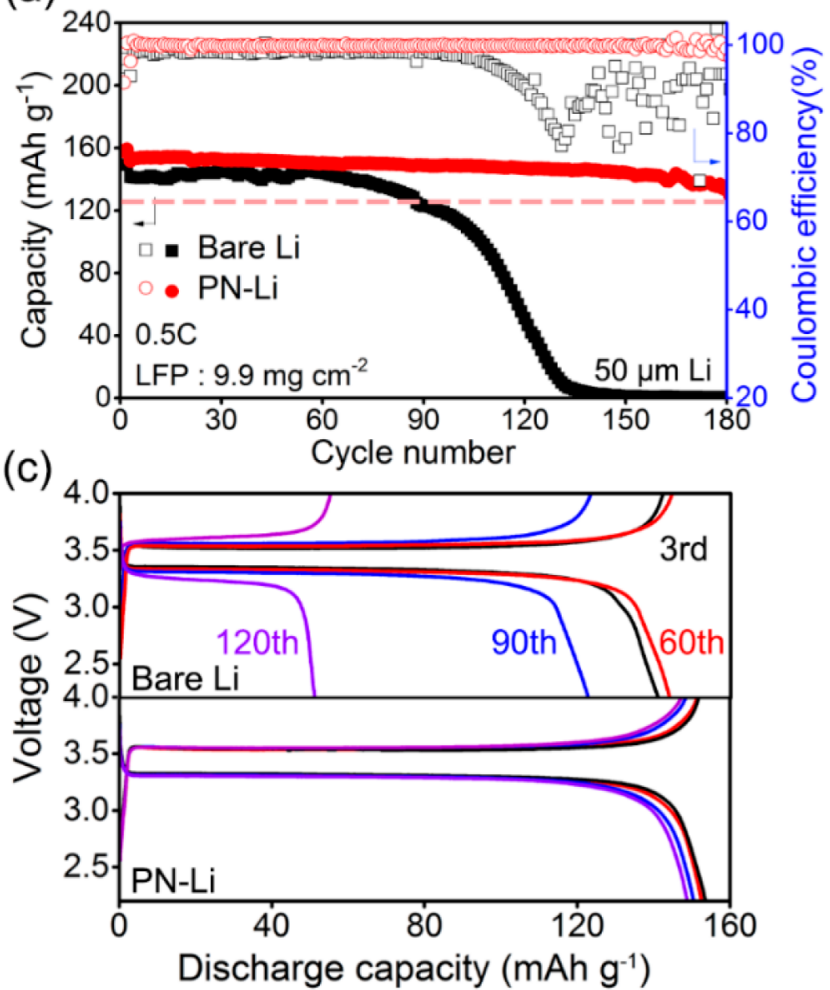

(b)

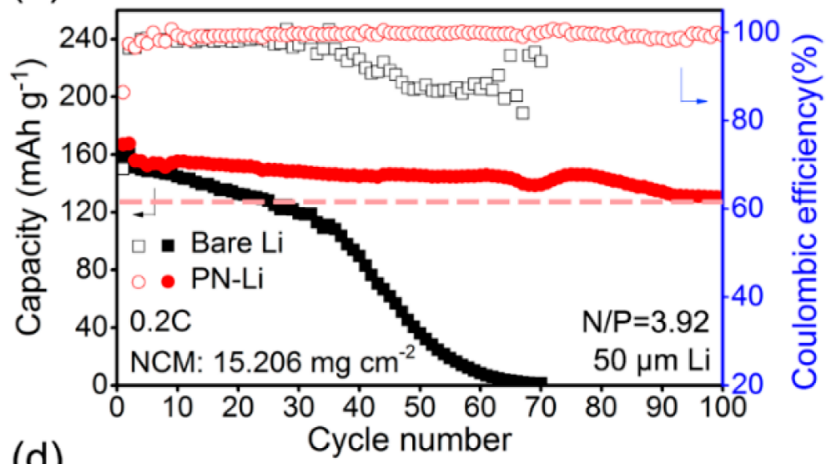

(d)

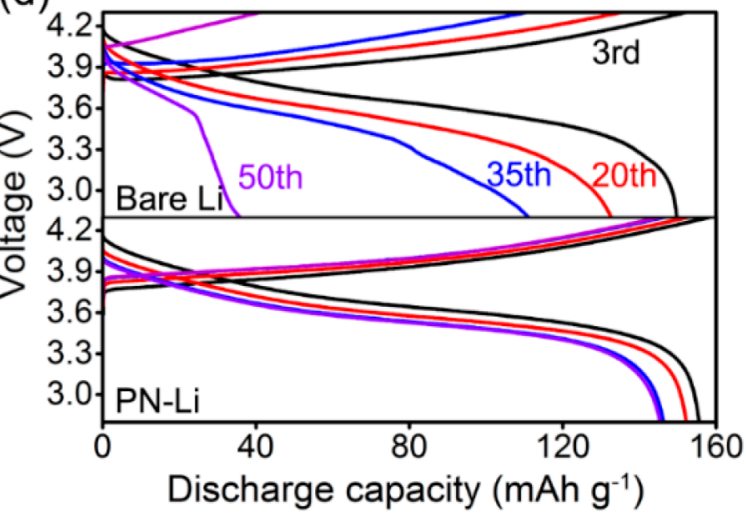

Figure 4. Electrochemical performance of $\mathrm{Li} / \mathrm{LFP}$ and $\mathrm{Li} / \mathrm{NCM} 523$ full cells. Long-term cycling performance of (a) $\mathrm{Li} / \mathrm{LFP}$ and (b) Li/ NCM523 full cells with mass loadings of 9.9 and $15.206 \mathrm{mg} \mathrm{cm}^{-2}$. (c) Voltage profiles of bare Li/LFP and PN-Li/LFP cells at different cycles. (d) Voltage profiles of bare Li/NCM and PN-Li/NCM cells at different cycles.

$\mathrm{mA} \mathrm{h} \mathrm{cm}{ }^{-2}$, respectively. Figure $4 \mathrm{a}$ shows the long cycling stability of $\mathrm{PN}-\mathrm{Li} / \mathrm{LFP}$ and bare $\mathrm{Li} / \mathrm{LFP}$ at a $0.5 \mathrm{C}$ rate $(1 \mathrm{C}=$ $170 \mathrm{~mA} \mathrm{~g}{ }^{-1}$ ), from which a modified LFP cell possesses a higher and more stable cycling performance. Specifically, the initial specific capacity of $155 \mathrm{mAh} \mathrm{g}^{-1}$ is obtained by a modified LFP cell and maintains $86.4 \%$ capacity retention after 180 cycles. Meanwhile, the bare Li/LFP cell can only effectively work for around 90 cycles and drops fast to 0 $\mathrm{mAh} \mathrm{g}^{-1}$ at the $130^{\text {th }}$ cycle due to the depletion of the $\mathrm{Li}$ source in cells. The Coulombic efficiency confirms the lithium exhaustion in cells that the bare Li cell shows a declined CE after 90 cycles, while the $\mathrm{PN}-\mathrm{Li}$ cell provides a high average $\mathrm{CE}$ of $99.8 \%$ during the whole cycling. The lithium exhaustion becomes more worse when the $\mathrm{N} / \mathrm{P}$ ratio arrives at 3.92 by using an NCM cathode (Figure $4 \mathrm{~b}$ ). The bare Li/NCM cell has a $80 \%$ capacity retention of 25 cycles and quickly fails after 60 cycles at such a high $\mathrm{N} / \mathrm{P}$ ratio. The cycled bare Li cell is disassembled, and remaining $\mathrm{Li}$ is measured to be $0.158 \mathrm{~mA} \mathrm{~h}$ $\mathrm{cm}^{-2}$, which is difficult for normal operation (Figure S17). As a comparison, the $\mathrm{PN}-\mathrm{Li} / \mathrm{NCM}$ cell successfully works for more than 100 cycles with a high CE of $99.8 \%$, which displays a 4 fold improvement in cell lifetime. The superior cycling performance is also supported by the galvanostatic voltage profiles in Figure 4c,d in that reduced voltage hysteresis can be found in modified LFP and NCM cells after the $90^{\text {th }}$ and $20^{\text {th }}$ cycles, suggesting that faster charge-transfer behavior at the $\mathrm{PN} /$ electrolyte interface effectively improves the cycling performance.

In conclusion, a functional phosphating-nitriding interface has been developed to improve cycling reversibility as well as suppress dendrite growth in high-energy-density cells. The stable and high-ionic-conductivity interface consisting of inorganic $\mathrm{Li}_{3} \mathrm{PO}_{4}, \mathrm{Li}_{3} \mathrm{~N}$, and nanocrystalline $\mathrm{LiCl}$ offers a high ionic pathway for fast $\mathrm{Li}^{+}$transfer. As a result, symmetrical $\mathrm{Li} / \mathrm{Li}$ cells utilizing $50 \mu \mathrm{m} \mathrm{Li}$ foils can operate steadily under an ultrahigh current density of $10 \mathrm{~mA} \mathrm{~cm}^{-2}$ using a conventional EC/DEC electrolyte. Owing to the homogeneous lithium electrodeposition behavior of the $\mathrm{PN}-\mathrm{Li}$ anode, the superior electrochemical cycling performance is achieved in high-capacity/high-voltage $\mathrm{NCM} / \mathrm{Li}$ full cells for 100 cycles with a low $\mathrm{N} / \mathrm{P}$ ratio of 3.92 . This work provides a promising route to synthesize a stable liquid-solid interface with optimized components to solve the uneven deposition with $\mathrm{Li}$ metal and sheds a new light on further research on an advanced artificial SEI layer for high-energy lithium-based batteries.

\section{ASSOCIATED CONTENT}

\section{S Supporting Information}

The Supporting Information is available free of charge at https://pubs.acs.org/doi/10.1021/acsmaterialslett.9b00416.

Experimental section; supporting tables and figures (PDF)

\section{AUTHOR INFORMATION}

\section{Corresponding Authors}

*E-mail: yingyinglu@zju.edu.cn. (Y.L.)

*E-mail: minling@zju.edu.cn. (M.L.)

ORCID $\odot$

Min Ling: 0000-0001-6727-9585

Yingying Lu: 0000-0001-9713-8441 


\section{Author Contributions}

"S.-Y.L. and Q.-L.L contribute equally to this work.

\section{Author Contributions}

All authors have given approval to the final version of the manuscript.

\section{Funding}

This work was supported by the National Key R\&D Program of China (2018YFA0209600, 2016YFA0202900) and the Natural Science Foundation of China (NSFC, grant number 21878268, 21676242).

\section{Notes}

The authors declare no competing financial interest.

\section{ACKNOWLEDGMENTS}

The authors thank Mrs. Na Zheng at the State Key Laboratory of Chemical Engineering in Zhejiang University for performing SEM and Raman. The authors also thank the support of the National Key R\&D Program of China (2018YFA0209600, 2016YFA0202900) and the Natural Science Foundation of China (NSFC, grant number 21878268, 21676242).

\section{ABBREVIATIONS}

LIB, lithium ion battery; LMBs, lithium metal batteries; SEI, solid electrolyte interface; CE, Coulombic efficiency; FIBSEM, focused ion beam scanning electron microscopy; DME, dimethyl ether; HRTEM, high-resolution transmission electron microscopy; XPS, X-ray photoelectron spectroscopy; EDS, energy dispersive spectroscopy; DFT, density functional theory; NMR, nuclear magnetic resonance

\section{REFERENCES}

(1) Armand, M.; Tarascon, J. M. Building better batteries. Nature 2008, 451, 652-657.

(2) Li, S.; Jiang, M.; Xie, Y.; Xu, H.; Jia, J.; Li, J. Developing HighPerformance Lithium Metal Anode in Liquid Electrolytes: Challenges and Progress. Adv. Mater. 2018, 30, 1706375.

(3) Li, L.; Li, S.; Lu, Y. Suppression of dendritic lithium growth in lithium metal-based batteries. Chem. Commun. 2018, 54, 6648-6661.

(4) Zeng, X.; Li, M.; Abd El-Hady, D.; Alshitari, W.; Al-Bogami, A. S.; Lu, J.; Amine, K. Commercialization of Lithium Battery Technologies for Electric Vehicles. Adv. Energy Mater. 2019, 9, 1900161.

(5) Fan, L.; Wei, S.; Li, S.; Li, Q.; Lu, Y. Recent Progress of the Solid-State Electrolytes for High-Energy Metal-Based Batteries. Adv. Energy Mater. 2018, 8, 1702657.

(6) Liu, J.; Bao, Z.; Cui, Y.; Dufek, E. J.; Goodenough, J. B.; Khalifah, P.; Li, Q.; Liaw, B. Y.; Liu, P.; Manthiram, A.; Meng, Y. S.; Subramanian, V. R.; Toney, M. F.; Viswanathan, V. V.; Whittingham, M. S.; Xiao, J.; Xu, W.; Yang, J.; Yang, X.-Q.; Zhang, J.-G. Pathways for practical high-energy long-cycling lithium metal batteries. Nat. Energy 2019, 4, 180-186.

(7) Lu, Y.; Rong, X.; Hu, Y.-S.; Li, H.; Chen, L. Research and development of advanced battery materials in China. Energy Storage Mater. 2019, 23, 144.

(8) Tikekar, M. D.; Choudhury, S.; Tu, Z.; Archer, L. A. Design principles for electrolytes and interfaces for stable lithium-metal batteries. Nat. Energy 2016, 1, 16114.

(9) Niu, C.; Pan, H.; Xu, W.; Xiao, J.; Zhang, J. G.; Luo, L.; Wang, C.; Mei, D.; Meng, J.; Wang, X.; Liu, Z.; Mai, L.; Liu, J. Selfsmoothing anode for achieving high-energy lithium metal batteries under realistic conditions. Nat. Nanotechnol. 2019, 14, 594-601.

(10) Niu, C.; Lee, H.; Chen, S.; Li, Q.; Du, J.; Xu, W.; Zhang, J.-G.; Whittingham, M. S.; Xiao, J.; Liu, J. High-energy lithium metal pouch cells with limited anode swelling and long stable cycles. Nat. Energy 2019, 4, 551-559.
(11) Ren, X.; Zou, L.; Cao, X.; Engelhard, M. H.; Liu, W.; Burton, S. D.; Lee, H.; Niu, C.; Matthews, B. E.; Zhu, Z.; Wang, C.; Arey, B. W.; Xiao, J.; Liu, J.; Zhang, J.-G.; Xu, W. Enabling High-Voltage LithiumMetal Batteries under Practical Conditions. Joule 2019, 3, 16621676.

(12) Li, S.; Liu, Q.; Zhou, J.; Pan, T.; Gao, L.; Zhang, W.; Fan, L.; $\mathrm{Lu}$, Y. Hierarchical Co3O4 Nanofiber-Carbon Sheet Skeleton with Superior $\mathrm{Na} / \mathrm{Li}$-Philic Property Enabling Highly Stable Alkali Metal Batteries. Adv. Funct. Mater. 2019, 29, 1808847.

(13) Li, Q.; Zhu, S.; Lu, Y. 3D Porous Cu Current Collector/LiMetal Composite Anode for Stable Lithium-Metal Batteries. Adv. Funct. Mater. 2017, 27, 1606422.

(14) Yun, Q.; He, Y. B.; Lv, W.; Zhao, Y.; Li, B.; Kang, F.; Yang, Q. H. Chemical Dealloying Derived 3D Porous Current Collector for $\mathrm{Li}$ Metal Anodes. Adv. Mater. 2016, 28, 6932-6939.

(15) Zheng, X.; Li, P.; Cao, Z.; Luo, W.; Sun, F.; Wang, Z.; Ding, B.; Wang, G.; Huang, Y. Boosting the Reversibility of Sodium Metal Anode via Heteroatom-Doped Hollow Carbon Fibers. Small 2019, $15,1902688$.

(16) Fan, L.; Li, S.; Liu, L.; Zhang, W.; Gao, L.; Fu, Y.; Chen, F.; Li, J.; Zhuang, H. L.; Lu, Y. Enabling stable lithium metal anode via 3D inorganic skeleton with superlithiophilic interphase. Adv. Energy Mater. 2018, 8, 1802350.

(17) Liu, S.; Xia, X.; Deng, S.; Xie, D.; Yao, Z.; Zhang, L.; Zhang, S.; Wang, X.; Tu, J. In Situ Solid Electrolyte Interphase from Spray Quenching on Molten Li: A New Way to Construct HighPerformance Lithium-Metal Anodes. Adv. Mater. 2019, 31, 1806470.

(18) Li, S.; Fan, L.; Lu, Y. Rational design of robust-flexible protective layer for safe lithium metal battery. Energy Storage Mater. 2019, 18, 205-212.

(19) Xu, R.; Zhang, X.-Q.; Cheng, X.-B.; Peng, H.-J.; Zhao, C.-Z.; Yan, C.; Huang, J.-Q. Artificial Soft-Rigid Protective Layer for Dendrite-Free Lithium Metal Anode. Adv. Funct. Mater. 2018, 28, 1705838.

(20) Jiang, Z.; Jin, L.; Han, Z.; Hu, W.; Zeng, Z.; Sun, Y.; Xie, J. Facile Generation of Polymer-Alloy Hybrid Layers for Dendrite-Free Lithium-Metal Anodes with Improved Moisture Stability. Angew. Chem., Int. Ed. 2019, 58, 11374-11378.

(21) Xu, R.; Cheng, X.-B.; Yan, C.; Zhang, X.-Q.; Xiao, Y.; Zhao, C.Z.; Huang, J.-Q.; Zhang, Q. Artificial Interphases for Highly Stable Lithium Metal Anode. Matter 2019, 1, 317-344.

(22) Ren, X.; Chen, S.; Lee, H.; Mei, D.; Engelhard, M. H.; Burton, S. D.; Zhao, W.; Zheng, J.; Li, Q.; Ding, M. S.; Schroeder, M.; Alvarado, J.; Xu, K.; Meng, Y. S.; Liu, J.; Zhang, J.-G.; Xu, W. Localized High-Concentration Sulfone Electrolytes for High-Efficiency Lithium-Metal Batteries. Chem. 2018, 4, 1877-1892.

(23) Chen, S.; Zheng, J.; Mei, D.; Han, K. S.; Engelhard, M. H.; Zhao, W.; Xu, W.; Liu, J.; Zhang, J. G. High-Voltage Lithium-Metal Batteries Enabled by Localized High-Concentration Electrolytes. Adv. Mater. 2018, 30, No. 1706102.

(24) Yan, C.; Yao, Y. X.; Chen, X.; Cheng, X. B.; Zhang, X. Q.; Huang, J. Q.; Zhang, Q. Lithium Nitrate Solvation Chemistry in Carbonate Electrolyte Sustains High-Voltage Lithium Metal Batteries. Angew. Chem., Int. Ed. 2018, 57, 14055-14059.

(25) Yang, Y.; Davies, D. M.; Yin, Y.; Borodin, O.; Lee, J. Z.; Fang, C.; Olguin, M.; Zhang, Y.; Sablina, E. S.; Wang, X.; Rustomji, C. S.; Meng, Y. S. High-Efficiency Lithium-Metal Anode Enabled by Liquefied Gas Electrolytes. Joule 2019, 3, 1986-2000.

(26) Fan, X.; Chen, L.; Borodin, O.; Ji, X.; Chen, J.; Hou, S.; Deng, T.; Zheng, J.; Yang, C.; Liou, S. C.; Amine, K.; Xu, K.; Wang, C. Nonflammable electrolyte enables Li-metal batteries with aggressive cathode chemistries. Nat. Nanotechnol. 2018, 13, 715-722.

(27) Weber, R.; Genovese, M.; Louli, A. J.; Hames, S.; Martin, C.; Hill, I. G.; Dahn, J. R. Long cycle life and dendrite-free lithium morphology in anode-free lithium pouch cells enabled by a dual-salt liquid electrolyte. Nat. Energy 2019, 4, 683-689.

(28) Zeng, Z.; Murugesan, V.; Han, K. S.; Jiang, X.; Cao, Y.; Xiao, L.; Ai, X.; Yang, H.; Zhang, J.-G.; Sushko, M. L.; Liu, J. Non-flammable 
electrolytes with high salt-to-solvent ratios for Li-ion and Li-metal batteries. Nat. Energy 2018, 3, 674-681.

(29) Zhang, Y.; Zhong, Y.; Shi, Q.; Liang, S.; Wang, H. Cycling and Failing of Lithium Metal Anodes in Carbonate Electrolyte. J. Phys. Chem. C 2018, 122, 21462-21467.

(30) Zhang, Y.; Zhong, Y.; Liang, S.; Wang, B.; Chen, X.; Wang, H. Formation and Evolution of Lithium Metal Anode-Carbonate Electrolyte Interphases. ACS Materials Lett. 2019, 1, 254-259.

(31) Kim, M. S.; Ryu, J.-H.; Deepika; Lim, Y. R.; Nah, I. W.; Lee, K.R.; Archer, L. A.; Il Cho, W. Langmuir-Blodgett artificial solidelectrolyte interphases for practical lithium metal batteries. Nat. Energy 2018, 3, 889-898.

(32) Wang, J.; Huang, W.; Pei, A.; Li, Y.; Shi, F.; Yu, X.; Cui, Y. Improving cyclability of $\mathrm{Li}$ metal batteries at elevated temperatures and its origin revealed by cryo-electron microscopy. Nat. Energy 2019, 4, 664-670.

(33) Hwang, J.-Y.; Park, S.-J.; Yoon, C. S.; Sun, Y.-K. Customizing a $\mathrm{Li}-$ metal battery that survives practical operating conditions for electric vehicle applications. Energy Environ. Sci. 2019, 12, 21742184. 